\title{
Fact vs. Fiction: An Exploratory Study of Graduation Rates of Division I Student-Athlete "Special Admits" Within a Single Conference
}

\author{
Alexandra Ingram, Ph.D. \\ University of Tennessee, Knoxville
}

Abstract: Within higher education, the enrollment of the "well rounded class" (i.e., special admits) as opposed to the "well rounded student" adds value to the diversity of the institution. Currently, the National Collegiate Athletic Association (NCAA) does not track the academic outcomes of student-athlete special admits. There is no data to suggest that those who are admitted at the lower end of the academic spectrum are those who are not graduating. Understanding this sub-population of student-athletes may aid in a better understanding of how to best help those with academic deficiencies, particularly since the NCAA's academic redshirt policy that went into effect in 2016. The first step to improving the graduation rate for future populations is to understand the current graduation landscape for all sub-populations. The purpose of this exploratory study was to gain an understanding of educational outcomes for Division I specially admitted student-athletes. In applying social cognitive theory to publicly available data and survey methods, findings showed the special admit population had a six-year graduation rate of 55\%. Only a small percentage (4.5\%) of special admits were dismissed for academic reasons. Thus, increasing the minimum initial eligibility requirements via academic redshirting may be an inefficient academic reform approach, as studies have shown that those who are redshirted their first year have poorer academic outcomes. Further study is suggested regarding the demographics and incoming academic characteristics of this population in order to pave the way for academic best practices for this severely understudied group of students within higher education.

Keywords: academic reform, Division I, higher education, intercollegiate athletics, special admits, social cognitive theory

\section{To Admit or Not to Admit?}

From pre-kindergarten to post-secondary education, recent decades have witnessed the growing importance, influence, and staying power of data-based accountability systems. Since the 1960's, the National Collegiate Athletic Association (NCAA) has collected increasing amounts of data and refined academic standards to better serve the various needs of student-athletes with a particular emphasis on academic success. However, a gap in this accountability system exists for the underserved and particularly academically vulnerable classification of special admits. Individuals who are specially admitted are those who do not meet standard academic requirements for the university. Little is known about graduation rates of special admits due to a lack of data and study on the topic. As a result, few understand the best way to assist this population in reaching eventual graduation. Without outcome data to reveal that student-athletes who are admitted at the lower end of the academic spectrum are those who are not graduating, significant changes to increase the minimum initial eligibility requirements and implementation of the academic redshirt policy may be an inefficient academic reform. 
This informational and research gap is accompanied by a lack of systemic, crossinstitutional consistency as to what constitutes a special admit. As the oversight body, the NCAA operates on the principle of academic institutional control and responsibility wherein admission policies are entirely the prerogative of the school, so long as student-athletes meet a minimal set standard required of all institutions. As a result, the NCAA does not require institutions to define special admittance policies or profiles for students who do not meet their respective university's admissions policies. Minimum admission requirements differ across institutions. As a result, a student-athlete may meet the admission requirements at one institution and not at another. Thus, a student-athlete could be a special admit at one institution and not a special admit at another in the same conference and/or state. Differences in admission requirements results in a failure to understand how to best serve this population.

There is a vast gap in the literature on student-athlete special admits. Prior research has focused on studying the college experience and graduation rates of specially admitted studentathletes at single institutions (Gurney et al., 2010; Robenolt, 2012). Alesia (2008) states, "Because there is no national statistic on graduation rates for special admits it is difficult to judge the degree to which schools are educating these athletes" (para. 37). Moreover, there is a gap in the literature for research that specifically looks at outcomes associated with student-athlete special admits across various institutions. Comeaux (2015) states, "Such insights are critical for forging deeper and creating more authentically responsive intervention strategies for athletes. In the absence of these materials, aspiring practitioners cannot be adequately prepared to fully develop the academic talents of college athletes" (p. xii). As such, it is imperative that studies focus on the graduation rates of such student-athletes.

Graduation outcomes in relation to incoming academic characteristics for student-athlete special admits should be where the focus lies. Former NCAA President Myles Brand explained:

The big question isn't whether athletes are as qualified as other students when they enroll, but whether, given help, they can obtain degrees. What you are really looking for is whether the student-athletes who are being accepted have the capability of graduating from that institution with the academic support they have available. (Knobler, 2008, para. 33)

Participation within collegiate athletics has the power to change lives. It allows individuals access to obtain a college degree, many of whom would not have been able to do so otherwise as a result of economic, personal, or academic reasons. For this reason, specially admitted, conditionally admitted, and academically at-risk student-athletes may have greater grit, drive, and motivation to succeed if they are given the right tools to do so.

The big fear is that student-athlete special admits are not graduating at an acceptable rate, and possibly should not be admitted going forward. On one hand, it is expected that student-athlete special admits receive more academic services and graduate at higher rates. Would this mean other student-athletes are being left behind? Not necessarily. On the other hand, it is expected that student-athlete special admits face greater challenges and graduate at lower rates. Would this mean that our institutional efforts are futile? Again, not necessarily. If the results of the current study 
find that student-athlete special admits are graduating at similar rates as the regular student-athlete population and/or student body population, perhaps these two aspects are offsetting. Thus, the fear of student-athlete special admits not graduating at an acceptable rate can be put to rest in a way that preserves, and possibly enhances, the opportunities provided through special admission.

The research problem is that information on student-athlete special admits is lackluster. Since the NCAA does not require institutions to specifically track the academic outcomes of this population, little is known about the extent to which this population is graduating, especially in comparison to regularly admitted student-athletes and the general student body population. One would assume their graduation rates would be lower than the aforementioned populations. This could lead institutions to restrict the number of special admits enrolled at the institution. However, there is no data to date to show that this population has poorer academic outcomes.

The purpose of this exploratory and descriptive mixed-methods study was to illuminate previously obscure graduation rates of student-athlete special admits across a variety of Division I institutions in order to begin to fill the gap in our understanding of their academic outcomes. In relation to six-year graduation rates of specially admitted student-athletes, I examined progress towards graduation, or lack thereof, based on entry into the professional leagues, dismissal from the team for academic reasons, dismissal from team for reasons other than academic, voluntarily withdrawing from school, and/or transferring to another school. The resultant discussion will aid the NCAA and its member institutions to better serve student-athletes and to spark further interest and research to better understand and support this at-risk group of student-athletes.

\section{Review of the Literature}

\section{Student-Athlete Academic Success}

The NCAA refers to the Academic Progress Rate (APR) and student-athlete graduation rates as the main measures of academic success (NCAA Research, 2020). Two measures that are employed are the Federal Graduation Rates (FGR) and the Graduation Success Rate (GSR). The former is part of the Higher Education Act of 1972 and applies to all students, whereas the latter was developed by the NCAA in 2003 and applies only to student-athletes.

\section{Federal Graduation Rate}

The FGR is the only rate wherein a direct comparison between the general student population and student-athletes may be drawn (NCAA Research, 2020). The FGR measures firstyear, full-time student-athletes in a cohort who receive financial aid within their first year of enrollment. Student-athletes are considered an academic success if they graduate within six years of initial enrollment from their institution. The FGR makes no accommodations for transfers, midyear enrollees, "walk-ons or recruited walk-ons who might eventually receive an athletic scholarship after their first year of enrollment" (Ferris et al., 2004, p. 558). The 2017-2018 Division I APR cohort showed that approximately 20,400 (12\%) student-athletes were transfers (NCAA Research, 2019). Lifetime transfer rates will be higher, as some of the student-athletes in this cohort are first-year college students who may eventually transfer. Moreover, walk-ons and recruited walk-ons consist of approximately half of the student-athlete population for revenue and non-revenue sports alike (Ferris et al., 2004). 


\section{Graduation Success Rate}

The GSR begins with the FGR cohort and adds transfer students, mid-year enrollees, and non-scholarship student-athletes to the calculation (NCAA Research, 2015a). Student-athletes who leave the institution in good academic standing (i.e., maintained a GPA of 2.60 if transferring to a 4-year college or 3.30 if transferring to a 2-year college) and would have met NCAA progresstoward-degree requirements before exhausting athletics eligibility are removed from the cohort of their initial institution; however, if they transfer to another institution, they are added to the new institution's GSR (NCAA, 2015a). Student-athletes who leave their institution in good academic standing are not counted against the institution in the GSR calculation (NCAA, 2015b). In the FGR calculation, these student-athletes are considered non-graduates. Poor academic standing, on the other hand, is defined as: GPA or credit accumulation does not have them on-track to graduate in six years or less; 2.60 GPA requirement for transferring to a 4-year college are not met; or 3.30 GPA requirement of transferring to a 2-year college are not met. Student-athletes who leave an institution in poor academic standing are deemed non-graduates by both the FGR and GSR (NCAA, 2015b).

\section{Current Initial Eligibility Requirements}

Effective August 1, 2016, the NCAA raised minimum high school GPAs and standardized test scores for student-athletes initially enrolling in a collegiate institution as a full-time student (i.e., must pass 12 credit hours per fall and spring semesters; NCAA, 2020-2021). The decision to change the initial eligibility requirements was the belief that student-athletes have "much more control over their GPA day-to-day and less control over a one-time test score" (Hosick \& Sproull, 2012 , p. 3). The three classifications of student-athletes include full qualifier, academic redshirt, and non-qualifier.

\section{Full Qualifier}

Full qualifiers can compete, receive athletic scholarships, and practice in their first year as a result of meeting the following requirements: graduate from high school; meet the minimum cumulative GPA of 2.30 in the 16 core-courses outlined in Bylaw 14.3.1.2; complete ten of these 16 core-courses before their senior year of high school wherein seven of the ten must be in the area of English, math, or science; and meet the minimum combined score of 900 on the SAT critical reading and math sections or a minimum sum score of 75 on the ACT (NCAA manual, 2018-2019, p. 161).

\section{Academic Redshirt}

As part of the new initial eligibility requirements, the NCAA developed the term academic redshirt. Student-athletes who are academic redshirts would have been considered a full qualifier under the former GPA/test score sliding scale. Academic redshirts cannot compete during their first year of full-time collegiate enrollment, are eligible to receive athletic scholarships during this timeframe, and may practice during their first semester. After the first semester is complete, the student-athlete must be academically successful (i.e., complete nine credit hours) at their institution in order to practice for the rest of the year. Academic redshirts are those who meet the 
following requirements: graduate from high school; meet the minimum cumulative GPA of 2.00 in the 16 core-courses outlined in Bylaw 14.3.1.2; and meet the minimum combined score of 1020 on the SAT critical reading and math sections or a minimum sum score of 86 on the ACT (NCAA manual, 2018-2019, p. 161).

\section{Non-Qualifier}

Student-athletes who have yet to graduate high school, have not successfully completed the required core curriculum, or have not met the required minimum core-curriculum GPA and/or corresponding SAT/ACT score required for either qualifier or academic redshirt status are considered non-qualifiers. Non-qualifiers cannot compete, receive athletic scholarship, or practice during their first year. However, they can receive non-athletic financial aid within their first year if it is based on financial need only (NCAA manual, 2018-2019, p. 161).

\section{Student-Athlete Special Admits}

Ingram and Huffman (2017) conducted a study that focused on the graduation outcomes of student-athletes who were specially admitted within universities in the Power 5 conferences. The Power 5 conferences consist of the Atlantic Coast Conference (ACC), Big Ten Conference (B1G), Big 12 Conference, Pacific Coast Conference (PAC-12), and Southeastern Conference (SEC). Results revealed graduation outcomes for 66 first-year student-athletes who were accepted on a special admit basis to their respective institution. When transfers were considered as an academic success (GSR calculation), 70\% of student-athlete special admits graduated within six years of enrolling at their initial institution. However, when transfers were considered as academic failures, $52 \%$ of student-athlete special admits graduated within six years from their initial institution (FGR calculation). When transfers were removed from the equation and did not count as an academic success or failure, $63 \%$ of student-athlete special admits graduated within six years from their initial institution (see Table 1 for how transfers affect graduation rates). When using any of the three variations of graduation rates, the majority of student-athlete special admits graduated within six years from their initial institution (52\%), whereas $18 \%$ transferred, and $30 \%$ did not graduate. Of the $30 \%$ who did not graduate, $17 \%$ voluntarily withdrew, $6 \%$ were dismissed for academic reasons, $3 \%$ entered the professional league, $1 \%$ was dismissed for non-academic reasons, and $3 \%$ were classified as "other." 


\section{Table 1}

How Student-Athlete Special Admit Transfers Affect Graduation Rates

\begin{tabular}{ccc}
\hline Graduation Rate $(\%)$ & How Transfers Affect Calculation & How \% Was Calculated \\
\hline $70 \%$ & $\begin{array}{c}\text { Transfers considered academic success } \\
\text { (similar to GSR calculation) }\end{array}$ & $\begin{array}{c}46 \text { graduates out of } 66 \\
\text { total student-athletes }\end{array}$ \\
& $\begin{array}{c}\text { Transfers considered academic failure } \\
\text { (similar to FGR calculation) }\end{array}$ & $\begin{array}{c}34 \text { graduates out of } 66 \\
\text { total student-athletes }\end{array}$ \\
& Transfers removed from graduation rate & $\begin{array}{c}\text { 34 graduates out of 54 } \\
\text { total student-athletes }\end{array}$ \\
\hline
\end{tabular}

Note. Percentages have been rounded to the nearest whole number.

Institutions within the Power 5 conferences posted higher graduation rates for their studentathletes as a whole (68\%) in comparison to Division I student-athletes (67\%) and the Division I general student body (65\%) according to FGR calculations. This is irrespective of the fact that their student-athlete special admits graduated at a lower rate. GSR calculations showed a similar trend wherein student-athletes within the Power 5 conference institutions graduated at a higher rate $(85 \%)$ in comparison to Division I student-athletes $(83 \%)$. This finding is significant, as larger institutions may have more student-athlete special admits (Sack, 1987). Although the Power 5 institutions may have higher rates of student-athlete special admits, they still posted higher graduation rates in comparison to other conferences who may have had lower rates of studentathlete special admits.

The study conducted by Ingram and Huffman (2017) extended the literature by surveying and focusing on multiple institutions when looking at outcomes associated with student-athlete special admits and focused on one cohort (the 2009 cohort) as opposed to a multitude of cohorts. Moreover, the findings of the study are similar to prior research conducted by Robenolt (2012) but are inconsistent with the findings of Gurney et al. (2010). See Table 2 for a comparison of these research studies and findings. The current study focuses on institutions within a single Division I Football Championship Subdivision (FCS) Conference $(N=10)$. 
Table 2

Comparison of Research Studies

\begin{tabular}{cccc}
\hline Outcomes & $\begin{array}{c}\text { Ingram \& } \\
\text { Huffman (2017) }\end{array}$ & $\begin{array}{c}\text { Robenolt } \\
(\mathbf{2 0 1 2})\end{array}$ & $\begin{array}{c}\text { Gurney } \text { et al. } \\
(\mathbf{2 0 1 0})\end{array}$ \\
\hline Graduated from initial institution & $52 \%$ & $65 \%$ & $37 \%$ \\
Transferred from initial institution & $18 \%$ & $15 \%$ & $28 \%$ \\
Did not graduate & $30 \%$ & $20 \%$ & $27 \%$ \\
$\quad$ Dismissed for academics & $6 \%$ & $2 \%$ & $11 \% *$ \\
Dismissed for non-academics & $1 \%$ & N/A & N/A \\
Entered professional league & $3 \%$ & N/A & $14 \%$ \\
Voluntarily withdrew & $17 \%$ & $2 \%$ & N/A \\
Exhausted eligibility & N/A & $4 \% * *$ & $2 \%$ \\
Other & $3 \%$ & $12 \%$ & N/A \\
No information & N/A & N/A & $8 \%$ \\
Student-Body Graduation Rate & $65 \%$ & $75 \%$ & $56 \%$ \\
\hline Total Number Special Admits & 66 & 48 & 183 \\
Institution(s) & Power 5 & Div. I FBS in & Div. I FBS in \\
Cohorts & Conferences & PAC-12 & Midwest \\
\hline
\end{tabular}

*Note. Includes those who dropped out or were academically suspended.

**Note. Includes those who graduated after the 6-year cut-off for NCAA graduation.

There is no shortage of practical programs, national awards, other NCAA, and non-profit organizations that recognize special admits and individuals who begin in marginalized academic standing, graduate, and go on to be highly successful, whether that is on the field, court, and in life. For example, in conjunction with the Institute for Sport and Social Justice (formally known as the National Consortium for Academics and Sports), Scholar Baller sponsors the Academic Momentum Award. This award recognizes roughly 20 student-athletes yearly for their academic accomplishments. Recipients are recognized for demonstrating significant academic improvement throughout their collegiate careers. Giant Steps Awards honors a diverse group of individuals who have shown courage and triumph in the midst of adversity, broken down barriers for those who otherwise would not have had opportunities, and demonstrated the power of community activism through the power of sport. In addition, National STUDENT-Athlete Day recognizes those who have achieved excellence in academics and athletics while having made significant contributions to their institutions and communities. While these examples are only a handful of programs and 
awards, specially admitted student-athletes and those who begin college with marginal incoming academic characteristics have increasingly received these awards and recognitions.

Although collegiate athletics continues to be displayed in the limelight, the division between research and practice regarding best practices within academic support centers for student-athlete special admits continues to remain stagnant. Consequently, practitioners tend to be out of sync with the needs of student- athletes (Comeaux, 2015). Furthermore, Comeaux (2015) argues the academic concerns of Division I student-athletes are primarily the result of "an organizational learning problem of practitioners as opposed to an individual learning problem of athletes" (p. 2). In other words, practitioners should focus on where the deficits lie and determine how to mitigate these aspects. Bensimon (2015) states, "It is said that what is measured is what gets noticed" (p. viii). Evaluations provide an informed perspective about the major strengths and deficiencies of the academic processes available to student-athletes and allow for data-driven decisions to be made regarding the improvement of program goals and implementation strategies. The Coalition on Intercollegiate Athletics (COIA, 2005) suggest "campuses track the academic performance of scholarship athletes who enroll through special admissions, to permit better understanding of how successfully the campus supports the academic needs of these students and what costs to the campus this may involve" (p. 2). Moreover, without outcomes data, the NCAA and its member institutions cannot effectively provide academic support services for the studentathlete special admit population.

\section{Theoretical Framework}

Educators use theory and research as guides to understanding what individual students may need, how they develop, and how they learn. The $21^{\text {st }}$ century has brought a new era of focus for educators: the creation of learning and program standards. Effective educators are those who understand student growth/development and are able to use this understanding as a guiding tool when providing assistance as needed. The ways individuals currently see, understand, and deal with learners are influenced by historical, theoretical frameworks. Accordingly, the philosophical framework of social cognitivism was chosen as the lens through which to evaluate the impact of individual-level factors and institutional-level factors on the graduation rates of student-athlete special admits and student-athletes in general by providing a new perspective for student growth and development within intercollegiate athletics. The framework of social cognitivism is derived from Albert Bandura's (1986) Social Cognitive Theory (SCT), which has been applied in the fields of education, psychology, and communication. Bandura postulates that learning and human functioning occur in a social context that features dynamic and reciprocal interactions between an individual's cognitions and personal factors, environmental variables, and behavior (Bandura, 1986). Moreover, SCT emphasizes one's social influence on social reinforcement (internal and external).

SCT is comprised of three separate nodes: behavior, person, and environment. The behavior node is explored in detail in the current study through an examination of academic outcomes (i.e., graduation rates). The second node (person) is the focus of the researcher's study (in review), which analyzes the incoming academic characteristics (i.e., high school GPA and SAT/ACT score) and the demographics of Division I student-athlete special admits in relation to six-year graduation rates. The third node (environment) can be explored in future studies that focus on the specific types of academic services, programs, curricular offerings, and 
interventions that are employed within student-athlete academic centers. Being able to understand student-athlete special admits within a broader capacity (i.e., demographics, academics, environments) and how these interplay with each other will give us a greater understanding of how to best help this marginalized group.

The overarching goal of SCT is to explain how individuals regulate their behavior through control and reinforcement to achieve goal-directed behavior that can be maintained over time (Schunk, 1989). SCT highlights social influence and its emphasis on internal and external social reinforcement by considering the unique way in which individuals acquire and maintain behavior, as well as the social environment in which individuals perform the behavior (Bandura, 1986). Five constructs represent the major classes of processing and behaviorgenerating elements: (a) reciprocal determinism, (b) behavioral capability, (c) observational learning, (d) expectations, and (e) self-efficacy. These cognitive units dynamically and continuously interact with one's environment and social world around them to generate an individual's distinctive patterns of behavior.

SCT is a theory that accounts for an individual's past experiences, which is a factor of whether or not a behavioral action will take place. Past experiences can influence one's current expectancies, expectations, and reinforcements. Combined, these three concepts not only determine whether an individual will engage in a specific behavior, they also serve as a reasoning that helps to explain why an individual may choose to engage in a particular behavior or not. SCT adopts an agentic perspective to self-development, adaptation, and change (Bandura, 2001). An agentic perspective means an individual intentionally influences their dayto-day behavioral functions and ultimately, their life circumstances. This viewpoint posits that individuals are "self-organizing, proactive, self-regulating, and self-reflecting" (Bandura, 2001, p. 4). In essence, we are contributors to our life circumstances, not just products of them.

\section{Research Questions}

Based on an analysis of the gaps in the literature, the following four research questions and justifications guided the current study:

RQ 1: What are the reasons for determining a student-athlete is a special admit?

Justification: There is a lack of systematic, cross-institutional consistency as to what constitutes a special admit. Minimum admissions requirements differ across institutions. Thus, a student-athlete may meet the admissions requirements at one institution and not at another.

RQ 2: What is the graduation rate for student-athlete special admits who graduate within six years at each of the sampled universities?

Justification: "Because there is no national statistic on graduation rates for special admits it is difficult to judge the degree to which schools are educating these athletes" (Alesia, 2008, para.

37). 
RQ 3: Is the percentage of student-athlete special admits who graduate within six years significantly different from that of the percentage of regularly admitted student-athletes who graduate within six years and the general student body cohort who graduate within six years?

Justification: "There is little research indicating that specially admitted student-athletes with lower scores are graduating at a lower rate than other student-athletes or the general student population" (Ingram \& Huffman, 2017, p. 3).

RQ 4: For the student-athlete special admits who did not graduate, what are the reasons for not graduating?

Justification: Such insights are critical for forging deeper and creating more authentically responsive intervention strategies for athletes (Comeaux, 2015).

\section{Methodology}

Athletic administrators within a single NCAA Division I FCS Conference were invited to participate in the study. This purposeful sample consisted of directors and associate directors of the academic center for student-athletes, faculty athletics representatives, and athletic eligibility officers. This specific conference, which consisted of 10 institutions, was chosen due to the diversity of member institutions: football and non-football schools; public, private, and military; and student enrollment that ranged from 1,600 students to 19,400 students. This diversity is representative of a broader segment of Division I student-athletes. Since there are no current data that show whether FCS institutions have more (or fewer) student-athlete special admits than the autonomy 5 conferences (i.e., Power 5 Conferences), the researcher does not seek to generalize the overall student-athlete data as representative of all Division I institutions - only Division I FCS institutions. The selection of one athletic conference allowed the researcher to maintain a small and manageable size of participants and data. The researcher plans to expand to other conferences in future research.

This study consisted of two data collection phases: publicly available data and a studentathlete special admit survey. Publicly available data were obtained for all 10 of the institutions, regardless of their participation in the study or not. Data obtained through publicly available data sources were taken from the NCAA Searchable Database, institution websites, press releases, and data published by the U.S. Department of Education. Data collected included single-year data for institutional aspects, such as student-athlete GSR, student-athlete FGR, and student body FGR for each of the six years between 2012 and 2017. As a result, a total of 18 data points were collected. Since the researcher pulled the needed information herself, this served to increase the validity of the data being collected.

Of the 10 institutions, six decided to participate in the second data collection phase, a student-athlete special admit survey. The survey was distributed to the director and assistant directors of the academic center for athletics at each institution. Additional staff members (e.g., eligibility specialist, faculty athletics representative, and academic coordinators) were included on the email as well to increase participant accountability. Each of the participating institutions selected an individual to complete this survey portion of the research. Individuals were those with access to individual-level data for specially admitted student-athletes who were admitted to the 
institution during the Summer and/or Fall 2011 semester. Data were obtained for 22 student-athlete special admits wherein 16 came from the same institution. To ensure data accuracy, individuals who completed the surveys on behalf of their institution were asked to provide institution name in addition to their name (both of which were for researcher use only and were removed from this particular publication). Participants completed an online survey created by the researcher and delivered electronically using QuestionPro, a web-based survey software tool. Data collected included:

- The number of first-year student-athletes admitted in the Summer and/or Fall of 2011 on a "special admit" basis.

- The "special admit" process for student-athletes at their institution; and

- Graduation Outcomes: Graduated from the institution within six years; did not graduate from the institution within six years; and reason for not graduating (if applicable; see Appendix A for details).

For research question one, qualitative techniques were employed wherein Boyatzis' (1998) thematic analysis was used to determine the specific reasons a student-athlete was considered a special admit. The researcher grouped the information into common themes in order to make valid inferences through inductive coding (Boyatzis, 1998; Krippendorff, 2013). Data for this question were collected from a total of six faculty athletic representatives from each of the six participating institutions via the student-athlete special admit survey. Within this survey, participants were given the opportunity to elaborate on the student-athlete special admit process regarding the data collected for the 22 student-athlete special admits.

For research question two and three, the overall six-year graduation rates of student-athlete special admits, student-athletes, and the student body per institution were obtained. For all three populations, the six-year graduation rate was for the 2011 cohort. Data were collected from the student-athlete special admit survey, the NCAA searchable database, the U.S. Department of Education website for student-athlete special admits, student-athletes, and the student body cohort respectively.

For research question four, descriptive data were collected from the survey regarding specific reasons student-athlete special admits did not graduate within six years. Data were compared across the 22 student-athlete special admits through the usage of means and frequencies. Respondents could select from a variety of non-graduation outcomes as described by the NCAA. The complete list is provided in Appendix A. In addition, "Other" was provided as a possible response. However, no respondents selected this option.

To assure reliability of the survey instrument, the researcher solicited opinions from two faculty athletics representatives at institutions not affiliated with the participating conference to determine whether there was similarity in the understanding of terms used. Based on the feedback from the experts, the researcher modified the instrument as needed by clarifying, adding, and/or deleting survey questions. To assure validity of the survey content, the researcher solicited opinions of experts, which included two NCAA National Office Staff Directors. The researcher enlisted the assistance of the official athletics' websites for each of the 10 institutions within the target population to determine contact information. 


\section{Findings}

For the purposes of this research, the 10 institutions within the conference were given pseudonyms: Alpha, Bravo, Charlie, Delta, Echo, Foxtrot, Romeo, Sierra, Tango, and Zulu. Of the 10 institutions within the conference, six chose to participate: Bravo, Charlie, Delta, Echo, Sierra, and Tango. Reasons for determining whether a student-athlete is a special admit included aspects such as: earning below an 18 on the ACT; earning below a 1030 on the SAT; not meeting the sliding scale of at least a 2.85 high school GPA and 18 ACT score; or not meeting the sliding scale of at least a 2.50 high school GPA and 21 ACT score. For participating institutions, the number of student-athletes specially admitted during the Summer and/or Fall of 2011 ranged from 0 to 16. Charlie had one special admit, Sierra had two special admits, Bravo had three special admits, and Tango had 16 special admits. Two of the six institutions indicated they did not have any studentathlete special admits (Delta and Echo). Reasons included having a holistic admissions process or a lack of remedial coursework at their institutions. Regarding the holistic admissions process, Echo indicated they "technically" have special admits at their institution; however, due to their holistic admissions process, these students are not flagged as such within their profile/system. Bravo indicated they typically have more student-athlete special admits; however, their institution was recently exiting an APR penalty season. As a result, Bravo was risk averse during the Summer/Fall 2011 admissions process regarding student-athlete special admits.

In addition to their one special admit, Charlie indicated they also had three conditional admits during the fall of 2011. All three had previously attended private high schools and had high school GPAs and SAT/ACT scores that met the institution's requirements; however, all were missing one high school unit needed for institutional admission. As a result, the three studentathletes took a visual arts course during the summer prior to their fall semester to make up for their high school deficiency. Charlie noted that these student-athletes probably would not have had a high school deficiency if they had attended a public school.

Student-athlete special admits represented $1.6 \%$ of the student-athlete population for participating institutions with special admits during the 2011 year. Within the participating institutions, the FGR for student-athlete special admits who graduated within six years from their initial institution was 55\%. This rate was identical to the six-year graduation rates of the student body cohort and similar to the six-year graduation rates of student-athletes in general (see Table 3). In addition, $9 \%$ transferred to another institution and $36 \%$ did not graduate. Of the $36 \%$ of student-athlete special admits who did not graduate, $4.5 \%$ were dismissed for academic reasons, $9 \%$ were dismissed for non-academic reasons, $4.5 \%$ entered the professional league, and $18 \%$ voluntarily withdrew. 


\section{Table 3}

Findings of Current Study

\begin{tabular}{cc}
\hline Outcomes & Ingram (2021) \\
\hline Graduated from initial institution & $55 \%$ \\
4 years or less & $32 \%$ \\
5 years & $23 \%$ \\
Transferred from initial institution & $9 \%$ \\
Did not graduate & $36 \%$ \\
Dismissed from team for academic reasons & $4.5 \%$ \\
Dismissed from team for non-academic reasons & $9 \%$ \\
Entered professional league & $4.5 \%$ \\
Voluntarily withdrew & $18 \%$ \\
General Student-Body Graduation Rate & $68 \%$ \\
\hline Total Number Special Admits & 22 \\
\hline
\end{tabular}

A comparison between student-athlete special admits and the student body cohort for the participating conference, DI institutions, and FCS institutions was made by looking at graduation rates (2017 FGR) through the usage of publicly available data. The N-1 chi-square test for association showed that there is no statistically significant association between student type (i.e., student-athlete special admit, student-athlete, or general student body) and whether the individual graduated within six years. In other words, student-athlete special admits, student-athletes, and non-athletes graduated within six years at comparably equal rates. A subsequent $\mathrm{N}-1$ chi-square test for association was run for the sub-population of 16 student-athlete special admits to discover if the shared experience of attending the same institution influenced the relationship between student type and whether the individual graduated within six years. No statistically significant association was found. 


\section{Discussion}

There are many assumptions regarding student-athlete special admits in their ability to compete in the classrooms based on standardized test scores and high school GPA; however, there is little research indicating that student-athlete special admits with lower scores are graduating at a lower rate than other student-athletes or the general student population. For example, NCAA managing director of research, Todd Petr, and consultant John McArdle of the University of Southern California found:

Predictors of academic success are better if the behavior on which the prediction is based on is closer in time to the academic outcome desired. For that reason, much of the NCAA initial-eligibility research is couched as being predictive of first-year collegiate success, not eventual degree attainment. (Hosick \& Sproull, 2012, p. 33)

In addition to predictors of academic success, situational aspects are significant as well. Situational factors have been shown to impact academics. Research has shown that when studentathletes truly feel as if they are part of a team, it can positively impact individual self-efficacy and subsequent individual performance (Hanton \& Jones, 1999). One could argue that decreased selfefficacy in sport has the ability to negatively impact academics, especially if a student-athlete had previously held high levels of self-efficacy within the athletics realm over academics. Ingram and Huffman (2017) noted that the "academic redshirt policy could have unintended consequences similar to the effects student-athletes experience when they are injured" (p. 6). Injured studentathletes can experience negative psychological effects, i.e., depression, when one does not feel like part of the team due to significant playing time losses, participating in workouts and/or practices, or traveling with the team for games. Models have shown that merely increasing admissions selectivity does not result in increased graduation rates (Francesconi et al., 2011). Without outcome data that reveal if student-athletes who are admitted at the lower end of the academic spectrum are those who are not graduating, significant changes to increase the minimum initial eligibility requirements and implementation of the academic redshirt policy may be an inefficient academic reform.

Regarding this research study, the academic redshirt policy was not yet in effect for the particular cohort that was studied (the 2011 cohort). The new academic redshirt policy is based on an academic sliding scale wherein the higher a student-athlete's high school GPA, the lower the standardized test score needs to be to meet the NCAA initial eligibility standards. Academic redshirts are those who have a high school GPA between 2.00 and 2.30, in addition to meeting the minimum combined score of 1020 SAT for critical reading and math sections or a minimum sum score of 86 on the ACT (combined score of the math, English, science, and reading sections wherein the max score for each section is a 36; NCAA manual, 2020-21, p.167). It could be possible that those who were deemed student-athlete special admits for this study would now be considered NCAA academic redshirts. 
The current findings begin to provide insight that student-athlete special admits are capable of graduating at the same rate as the regularly admitted student body cohort and student-athlete cohort. Regarding the six-year graduation rates of student-athlete special admits, the findings for this study align well with previous research conducted by Ingram and Huffman (2017) and Robenolt (2012), but the findings are inconsistent with the findings of Gurney et al. (2010). The current study revealed the six-year graduation rates of student-athlete special admits was 55\%, whereas other studies revealed rates of 52\% (Ingram \& Huffman, 2017), 65\% (Robenolt, 2012), and $37 \%$ (Gurney et al., 2010). One reason for this inconsistency could be due to the span of years that the researchers used as a focus. Ingram and Huffman (2017) focused on 66 student-athlete special admits within the Power 5 Conferences from the 2009 cohort; Robenolt (2012) focused on 48 student-athlete special admits who were admitted to a PAC-12 institution, the University of Washington from 2003 to 2005; Gurney et al. (2010) focused on 183 student-athlete special admits at a NCAA FBS university in the Midwest from 1998 to 2003. Results from the current study extend the literature by surveying multiple institutions when examining outcomes associated with student-athlete special admits and focusing one cohort (the 2011 cohort), as opposed to a multitude of cohorts.

The findings from the current research also showed that $9 \%$ of student-athlete special admits transferred from their initial institution. Prior research revealed 18\% (Ingram \& Huffman, 2017), 15\% (Robenolt, 2012), and 28\% (Gurney et al., 2010). Conversely, this study revealed only $4.5 \%$ of student-athlete special admits were dismissed for academics. Prior research regarding academic dismissal was 6\% (Ingram \& Huffman, 2017), 2\% (Robenolt, 2012), and 11\% (Gurney et al. (2010). One observation to note is that the $11 \%$ reported by Gurney et al. (2010) includes a combination of student-athletes who either dropped out or were suspended for academics (see Table 4). 
Table 4

Comparison of Research Studies

\begin{tabular}{ccccc}
\hline Outcomes & $\begin{array}{c}\text { Ingram } \\
(\mathbf{2 0 2 1})\end{array}$ & $\begin{array}{c}\text { Ingram \& } \\
\text { Huffman } \\
(\mathbf{2 0 1 7})\end{array}$ & $\begin{array}{c}\text { Robenolt } \\
(\mathbf{2 0 1 2})\end{array}$ & $\begin{array}{c}\text { Gurney et al. } \\
(\mathbf{2 0 1 0})\end{array}$ \\
\hline $\begin{array}{c}\text { Graduated from initial institution } \\
\text { 6 years or less }\end{array}$ & $55 \%$ & $52 \%$ & $65 \%$ & $37 \%$ \\
$\quad$ Transferred from initial institution & $9 \%$ & $18 \%$ & $15 \%$ & $28 \%$ \\
Did not graduate & $36 \%$ & $30 \%$ & $20 \%$ & $27 \%$ \\
$\quad$ Dismissed for academics & $4.5 \%$ & $6 \%$ & $2 \%$ & $11 \% *$ \\
$\quad$ Dismissed for non-academics & $9 \%$ & $1 \%$ & N/A & N/A \\
Entered professional league & $4.5 \%$ & $3 \%$ & N/A & $14 \%$ \\
$\quad$ Voluntarily withdrew & $18 \%$ & $17 \%$ & $2 \%$ & N/A \\
$\quad$ Exhausted Eligibility & N/A & N/A & $4 \% * *$ & $2 \%$ \\
$\quad$ Other & N/A & $3 \%$ & $12 \%$ & N/A \\
No information & N/A & N/A & N/A & $8 \%$ \\
General Student-Body Graduation Rate & $68 \%$ & $65 \%$ & $75 \%$ & $56 \%$ \\
\hline Total Number Special Admits & 22 & 66 & 48 & 183 \\
Institution(s) & Div. I FCS & Power 5 & Div. I FBS in & Div. I FBS in \\
Cohorts & One & One & Multiple & Multiple \\
& (Fall 2011) & (Fall 2009) & $(2003-2005)$ & $(1998-2003)$ \\
\hline
\end{tabular}

*Note. Includes those who dropped out or were academically suspended.

**Note. Includes those who graduated after the 6-year cut-off for NCAA graduation.

Within this study, the biggest reason for non-graduation was voluntarily withdrawing from the institution (18\%). Of those who voluntarily withdrew, reasons included dislike of participating on the sport team or were classified as "unknown." Reasons for voluntarily withdrawing may have consisted of, but are not limited to: lack of playing time; loss of scholarship monies; being diagnosed with a life-threatening illness or mental health issues; family complications or emergencies; becoming pregnant; harassment; meeting the requirements for an athletics activities waiver (e.g., competing in the Olympics); extreme financial difficulties as a result of a specific event; and deceased, and/or permanently disabled. Furthermore, studies have shown that those who fail to graduate rarely do so for academic reasons, as many have family issues and/or financial issues as well (Johnson, 2000-2001; Sullivan \& Nielsen, 2013; Tinto, 1993). The same may be 
true for those who voluntarily withdraw. Institutions must recognize these barriers for retention and proactively intervene when possible. Otherwise, administrators are not pragmatically achieving their educational and athletic goals.

Although this study consisted of 22 student-athlete special admits, wherein 16 came from the same institution, results revealed that student-athlete special admits had the same six-year graduation rates as the student body cohort within FCS institutions (across the nation) as a whole. While there was no statistically significant difference in the graduation rates between the general student body cohort, student-athletes, and student-athlete special admits, this is not to say that student-athlete special admits are otherwise similar to these sub-populations. The student-athlete special admit population differs from the general student body and student-athlete cohorts, as the incoming academic characteristics and associated social implications across these populations are vastly different. Academic deficiencies are merely one facet that student-athlete special admits encounter.

As a first-year college student, one must deal with the pressures of a new environment academically, socially, mentally, and physically (e.g., changes in one's diet due to meal plans) in addition to the possibility of being away from their family for the first time. Student-athletes often experience blurred lines between their academic demands and their athletic demands. Both require different roles, yet similar expectations. The participatory effects in one domain often spill over into the next (Browning, 2015). Student-athletes shoulder a tremendous amount of responsibility regarding the time demands related to athletic pursuits (e.g., practice, film review, travel, competition, weight training, physical therapy, media responsibilities, and community service) in addition to being thrust into the limelight as a college athlete.

Individuals with lower academic preparedness and/or academic deficiencies tend to need additional support to successfully transition to college. Some may need validation that they belong on campus and are capable of succeeding in a college environment (Engle \& Tinto, 2008). Academically at-risk students and/or special admits may be required to enroll in developmental coursework, which consequently can impact confidence levels in their ability to become academically successful (i.e., academic self-esteem). As a student-athlete, they receive a double whammy if their athletic self-esteem spirals due to playing time loss, being sidelined from an injury, or not participating on the travel team (i.e., academic redshirts), especially if they had previously held high levels of self-efficacy within the athletics realm over academics. Moreover, special admits may face the stigma that their college admittance is based solely on affirmative action rather than their academic abilities, further decreasing their academic self-esteem (ASHE, 2013).

Not only do student-athlete special admits face the aforementioned constraints (e.g., firstyear college student, student-athlete, and special admit), they may also face additional challenges if they are a first-generation college student and/or from a low-income household. First-generation college students and those from low-income households may face distinctive challenges such as: insufficient levels of emotional support from immediate family members due to a limited understanding of the commitment necessary for a student to thrive in college (e.g., academic rigor and expectations); inside knowledge on how the college system works; how to apply and receive financial aid; how to choose a major; unfamiliarity with the college curriculum; college readiness; 
and financial stability (Falcon, 2015; Sparkman et al., 2012). Furthermore, racial underrepresentation, low academic self-esteem, and difficulty adjusting to college can manifest while enrolled (Stephens et al., 2014). Not only do these students face academic and social barriers, they may also face obstacles with respect to "cultural adaptation (i.e., norms, values, expectations) due to the differences between the culture of their families and communities and the culture that exists on college campuses" (Engle \& Tinto, 2008, p. 21). As a result, it is easy to see why firstgeneration college students are more likely to struggle to find their place within higher education and may feel left out (Stephens et al., 2014).

In dealing with underserved groups (i.e., student-athlete special admits), the focus should be on improving the deficits and equalizing the academic playing field. However, one cannot do so without first establishing an understanding that education is not a one-size-fits-all model. Not only is collegiate athletics considered a culture in and of itself, what works for one student-athlete may not work for another. Based upon the findings of the current study, the reasons for determining whether a student-athlete is a special admit is a valid construct. While the admissions standards and processes for special admits varies across institutions, the fact remains that these studentathlete special admits are individuals who would not have been admitted to the institution under their normal entrance requirements without the usage of a special and/or holistic admissions process. Not only are these student-athletes distinctive from their student-athlete peers and student body cohort due to academic deficiencies, the social implications that stem from these academic deficiencies are another aspect that further validates the uniqueness of being a student-athlete special admit.

Data-driven best practices within intercollegiate athletics for student-athlete special admits are limited. One cannot determine if the current academic programs are effective in meeting the needs of the student-athlete special admit population, nor do we understand the impacts of these programs on participants' knowledge levels, attitudes, and behaviors. Without data tracking these student-athlete special admits and understanding best practices in which academic programs are most beneficial to this population, there is no evidence to ensure institutions are meeting their mission of creating a successful future for all students enrolled within the university. Finally, with the implementation of the NCAA Academic-Based Revenue Distribution beginning in 2020, institutions will be looking for ways to meet these academic standards in order to receive a share of this distribution. Academic best practices for their student-athletes, especially their special admit population, will begin to move to the forefront.

Special admits are individuals with incoming academic deficiencies; however, when referencing data from the current study, one cannot tell. Since they are graduating at comparable rates, this would lead one to believe that the existing interventions and academic support systems currently in place for these institutions are efficacious (e.g., study hall requirements, obtainment of academic mentors and tutors, development programs, etc.). The data affirm that change does not need to take place regarding the current academic support programs student-athletes receive at the institutional level for participating institutions within this study. The outlier in this statement (i.e., student-athletes who are redshirted their first year) do not seem to fare well, irrespective of the types of academic support programs currently in place. However, it would be important to analyze the specific academic support systems that are being used, particularly as they relate to the student-athlete special admit population. Other institutions can benefit from these findings, 
especially if they are institutions with student-athlete special admits who have poor academic outcomes or are looking to improve the graduation rates for this specific population. The data show that there is an organizational learning problem for student-athletes who are redshirted their first year. Regardless of the reason for redshirting, this has a detrimental effect on student-athlete graduation rates. While the academic redshirting policy was not yet in effect for this study, several individuals from this study who were not redshirted for other reasons would have fallen into the academic redshirting requirement. The academic support programs that work for student-athletes and student-athlete special admits in helping them obtain six-year graduation rates does not seem to offset the effects of redshirting within their first year.

In relation to the study at hand, the researcher hopes to begin a discussion that will ultimately lead to improved academic outcomes (i.e., higher GPAs, increased graduation rates) for this previously understudied population of student-athletes. The resultant discussion will aid the NCAA and its member institutions to greater serve student-athletes and spark further interest/research to better understand and support this academically at-risk group of studentathletes. SCT details the bi-directional aspects between person, behavior, and environment. This manuscript only focuses on the behavior aspect of SCT, which is defined as student-athlete special admit six-year graduation rates. Further studies are needed that focus on the two additional aspects of SCT: one to focus on person, e.g., student-athlete special admit demographics and incoming academic characteristics, and one to focus on environment, e.g., academic support programs in place for student-athlete special admits. By using the additional nodes of SCT in conjunction with the current research, scholars will be able to obtain a greater appreciation from a holistic perspective as to how student-athlete behavior (graduation rates), person (demographics and incoming academic characteristics), and environment (institutional academic support programs) have a bi-directional impact on one another. More specifically, the findings will aid in the development of establishing a clear understanding of what this unique population needs in order to develop a roadmap of academic best practices and maximize student success in graduating within six years.

\section{Limitations}

Because of the boundaries set for this study, some limitations exist. Due to the participation rate associated with the dataset in this study (22 student-athlete special admits, wherein 16 came from the same institution), the findings should not be regarded as conclusive for this conference because it does not account for institutional differences such as size, public vs. private organization type, and institutional definitions or interpretations of a special admit. It is likely that more generalizable information will be generated by greater participation. The expectation is that a greater number of student-athlete special admits can achieve academic success and eventual graduation once more detailed and specific information on common outcomes associated with this unique population are uncovered.

Another limitation of this study is that there is currently no agreed upon definition of special admit from institution to institution. Institutions vary widely in the types of student-athletes they admit (i.e., a student-athlete may be considered a special admit at one institution wherein they may be considered a regular admit at another). The NCAA initial eligibility requirements simply serve as guidelines, not an aspect to be generalized to all universities. This challenge is intensified 
by the fact that "the NCAA eligibility requirements are more restrictive than the admission requirements of approximately 25\% of Division I-A universities" (Ferris et al., 2004, p. 568). Placing parameters on the term special admit would be one way to alleviate this problem, e.g., student-athletes who scored one or two standard deviations lower than the average standardized test score for the incoming cohort. This recommendation would allow for the results to be comparable across various institutions.

An additional limitation consisted of the fact that 16 of the 22 student-athlete special admits came from the same institution. Thus, they may have a certain shared experience that makes them different from the six student-athlete special admits at the other participating institutions. Future research should explore these issues with student-athlete special admits across a wider variety of institutions and conferences. Last, in order to gain a deeper understanding of the Division I studentathlete special admit population, this study was limited to one cohort of student-athlete special admits. Future studies should focus on multiple cohorts across one institution or one cohort across several institutions.

\section{Recommendations for Future Studies}

Despite the low response rate, this study provides data that begins to fill in the gap in the literature regarding outcomes associated with student-athlete special admits across various institutions. Some findings associated with these variables have important implications. Taking the findings of this study into consideration, the following recommendations for future research are offered:

First, the findings from this study provide information regarding common outcomes that are associated with student-athlete special admits across multiple schools. Understanding the student-athlete special admit population is the first step to allowing for data-driven decisions to be made regarding the improvement of program goals and implementation. This will aid in the development of strategies that ensure student-athletes and student-athlete special admits will not only be able to achieve excellence on the field, but within the classrooms as well. Stakeholders must know the population they are dealing with before they can effectively offer assistance. Without knowledge of how the demographics and incoming academic characteristics of studentathlete special admits (i.e., high school GPA and SAT/ACT) impact graduation rates within the current educational landscape, one cannot successfully assist this population in increasing their academic and graduation outcomes.

The second recommendation is that the admission standards and processes for special admits should be considered for further research because they vary widely amongst institutions. This type of research would inform administrators of best practices regarding recruiting, enrolling, retaining, and graduating student-athlete special admits in order to ensure that they have a meaningful educational experience. Within this study, it was revealed that institutions disliked the term special admit. To prevent institutions from stating that they do not have special admits due to a holistic admissions process, future studies should request that participating institutions provide data for those who fall under a specific academic cut-off (e.g., those below NCAA initial eligibility standards). As such, a specific cut-off would allow institutions to accurately state that a studentathlete would not have been admitted to their institution if they solely used an academic admission 
process as opposed to a holistic process. The usage of this criteria along with access to the National Clearinghouse Database would allow for the NCAA or alternative researchers to conduct a wider and more comprehensive study regarding incoming academic characteristics and graduation outcomes.

Freshmen redshirting (whether they are an academic redshirt, medical redshirt, or athletic redshirt) is an added layer that must be examined by future research when looking at studentathlete special admits. Student-athlete special admits who are also redshirted their first year may present an additional risk in comparison to student-athlete special admits who are not redshirted their first year. Additionally, future research could operationalize special admit for research purposes as those who do not meet the NCAA requirements of being an academic redshirt (i.e., are a non-qualifier). This would allow the term to be standardized across institutions, as special admits are not always those who are considered non-qualifiers due to the varying admissions standards required by institutions.

As a result of these academic and social differences regarding student-athlete special admits, it is important for future studies to extrapolate these findings by focusing on (a) the demographics and incoming academic characteristics of this population; (b) specific academic support programs available to student-athlete special admits; and (c) which programs are most effective for this sub-population. Doing so will allow for further contribution of the SCT approach (i.e., person node and environment node) to aid in the holistic development of academic best practices for student-athlete special admits. Future research should parse out students who are specially admitted for significant academic deficits (i.e., lower GPA or test scores) rather than other admission weaknesses (e.g., lacking sufficient foreign language credits). Subsequently, athletic departments should develop, employ, and further validate evidence-based, best practices for supporting these students' academic success and timely graduation. Future research could examine the rationale for student-athletes who voluntarily withdraw from an athletics program. This would inform administrators on how to better retain student-athletes and provide necessary program and/or support as needed.

\section{Conclusion}

Results from this study indicate that the previously held assumption that special admits are not graduating at an acceptable rate might be an institutional myth. The majority of student-athlete special admits graduated from their respective initial institutions within six years, while only a small minority (4.5\%) of student-athlete special admits were dismissed for academic reasons. The findings showed that student-athlete special admits had the same six-year FGR as the student body cohort of all FCS institutions across the nation (55\%). Therefore, it may be argued that studentathlete special admits are, in general, capitalizing on their opportunity to earn a college education culminating in a degree (for personal gain) rather than being exploited as mere disposable labor with a short shelf-life (for the institution's gain). Thus, student-athlete special admits within higher education appear to be in a mutually beneficial relationship. To ensure students of an institution are sufficiently diverse, institutional stakeholders may agree that the value specially admitted student-athletes add to their campus is worth the search to enroll the well-rounded class instead of the well-rounded student. If so and based on the findings of this study, admitting student-athletes on a special admit basis is a pragmatic conclusion from a social cognitivism standpoint. 


\section{References}

Alesia, M. (2008, September 7). "Special” treatment for athletes. http://www.indystar.com/apps/pbcs.d11/article?AID=/20080907/SP

Association for the Study of Higher Education (ASHE). (2013). Challenges to Latino student success. ASHE Higher Education Report, 39(1), 39-52. https://doi.org/10.1002/aehe.20007

Bandura, A. (1986). Social foundations of thought and action: A social cognitive theory. Prentice Hall.

Bandura, A. (2001). Social cognitive theory: An agentic perspective. Annual Review of Psychology, 52(1), 1-26.

Bensimon, E. M. (2015). Forward. In E. Comeaux (Ed.), Making the connection: Data-informed practices in academic support centers for college athletes ( $\mathrm{p}$. vii-x). Information Age Publishing, Inc.

Boyatzis, R. E. (1998). Transforming qualitative information: Thematic analysis and code development. Sage.

Browning, A. (2015). Bridging the gap: Academic support for entering special-admit college athletes. In E. Comeaux (Ed.), Making the connection: Data-informed practices in academic support centers for college athletes (pp. 109-123). Information Age Publishing, Inc.

Coalition on Intercollegiate Athletics (2005). Academic integrity in intercollegiate athletics: Principles, rules, and best practices. http://www.thecoia.org/wpcontent/uploads/2014/07/Academic-Integrity-in-Intercollegiate-Athletics-2005.pdf

Comeaux, E. (Ed.). (2015). Making the connection: Data-informed practices in academic support centers for college athletes. Information Age Publishing, Inc.

Engle, J., \& Tinto, V. (2008). Moving beyond access: College success for low-income, firstgeneration students. Pell Institute for the Study of Opportunity in Higher Education. https://files.eric.ed.gov/fulltext/ED504448.pdf 
Falcon, L. (2015). Breaking down barriers: First-generation college students and college success. Innovation Showcase, 10(6).

Ferris, E., Finster, M., \& McDonald, D. (2004). Academic fit of student-athletes: An analysis of NCAA division I-A graduation rates. Research in Higher Education, 45(6), 555-575.

Francesconi, M., Aina, C., \& Cappellari, L. (2011). Student performance may not improve when universities are choosier. Evaluation and Research in Education, 24(4), 231-242. https://doi.org/10.1080/ 09500790.2011.623772

Gurney, G. S., Tan, D. L., \& Winters, C. A. (2010). Specially admitted student-athletes: Their academic performance, persistence, and graduation from an NCAA Football Bowl Subdivision university. International Journal of Sport Management, 11(3), 477-491.

Hanton, S., \& Jones, G. (1999). The effects of a multimodal intervention program on performers: II. Training the butterflies to fly in formation. The Sport Psychologist, 13(1), 22-41.

Hosick, M. B., \& Sproull, N. (2012). NCAA: Eligibility and success. Journal of College Admission, 217, 31-33.

Ingram (2021). Is there such a thing as too low? An exploratory study of incoming academic characteristics of division I student-athlete "special admits" in relation to six-year graduation rates. [Unpublished manuscript]. University of Tennessee, Knoxville.

Ingram, A. M., \& Huffman, L. T. (2017). To admit or not to admit? An exploratory study of graduation rates of "special-admit" student-athletes within the "Power 5" conferences. Journal for the Study of Sports and Athletes in Education, 11(3), 193-215. https://doi.org/10.1080/19357397.2017.1346749

Johnson, J. L. (2000-2001). Learning communities and special efforts in the retention of university students: What works, what doesn't, and is the return worth the investment? Journal of College Student Retention, 2(3), 219-238.

Knobler, M. (2008, December 30). AJC investigation: Many athletes lag far behind on SAT scores. The Atlanta Journal-Constitution. https://www.al.com/solomon/2008/12/admission_qualifications.html 
Krippendorff, K. (2013). Content analysis: An introduction to its methodology (3rd ed.) Sage.

National Collegiate Athletic Association. (2020-2021). NCAA division I manual. Indianapolis: NCAA.

NCAA Research Staff. (2015a). Trends in graduation success rates and federal graduation rates at NCAA division I institutions. National Collegiate Athletic Association. http://www.google.com/url?sa=t\&rct=j\&q=\&esrc=s\&source=web\&cd=1\&ved=0ahUKwi BjemZtcvLAhXI2SYKHa1aDXIQFggcMAA\&url=http\%3A\%2F\%2Fweb1.ncaa.org\%2F app_data\%2FGSR\%2Fnablus15\%2FGSR_Fed Trends.pdf\&usg=AFQjCNGZ9azeVI5IH YI0VD9uBY4oBFhelA

NCAA Research Staff. (2015b). How are NCAA graduation rates calculated? National Collegiate Athletic Association.

https://www.google.com/?gws_rd=ssl\#q=how+are+the+NCAA+graduation+rates+calcul ated +2015

NCAA Research Staff. (2019). Research on student-athlete transfers. National Collegiate Athletic Association. http://www.ncaa.org/about/resources/research-student-athlete$\underline{\text { transfers }}$

NCAA Research Staff. (2020). Division I academic progress rate (APR). National Collegiate Athletic Association. http://www.ncaa.org/about/resources/research/division-i-academicprogress-rate-apr

Robenolt, P. J. (2012). What's so special about intercollegiate athletic special admits? Implications for academic support programming [Unpublished doctoral dissertation]. University of Washington.

Sack, A. L. (1987). College sport and the student-athlete. Journal of Sport and Social Issues, 11(1-2), 31-48.

Schunk, D. H. (1989). Social cognitive theory and self-regulated learning. In B. Zimmerman \& D. Schunk (Eds.), Self-regulated learning and academic achievement: Theoretical perspectives (pp. 83-110). Springer. 
Sparkman, L., Maulding, W., \& Roberts, J. (2012). Non-cognitive predictors of student success in college. College Student Journal, 46(3), 642-652.

Stephens, N. M., Hamedani, M. G., \& Destin, M. (2014). Closing the social-class achievement gap: A difference-education intervention improves first-generation students' academic performance and all students' college transition. Psychological Science, 25(4), 943-953.

Sullivan, P., \& Nielsen, D. (2013). "Ability to benefit": Making forward-looking decisions about our most underprepared students. College English, 75(3), 319-343.

Tinto, V. (1993). Leaving college: Rethinking the causes and cures of student attrition (2nd ed.). University of Chicago Press. 


\section{Appendix A: Student-Athlete Special Admit Survey Questions}

1. Survey Information

a. Institution Name

b. Individual Name and Title Completing Survey

2. How many student-athletes at your institution were admitted during the Summer and/or Fall 2011 semester on a "special admit" basis?

"Special admit" is defined as a student-athlete who was admitted under a special exception to the university's normal entrance requirements (see NCAA manual, 2015, p. 151). A "special admit" is NOT necessarily a "non-qualifier."

3. For each student-athlete that was admitted on a special admit basis during the Summer and/or Fall 2011 semester, please provide their academic outcome...

a. Select which category the student-athlete falls under...

i. Graduated from the institution

1. In 4 years or less

2. In 5 years

3. In 6 years

4. In more than 6 years

ii. Transferred from the institution

iii. Did not graduate from the institution?

1. Dismissed from team for academic reasons

2. Dismissed from team for non-academic reasons

3. Voluntarily withdrew from the team

a. Mental health reasons

b. Health related injury

c. Academic major discontinued at institution

d. Financial reasons

e. Extenuating circumstances

f. Religious

g. Other (please specify)

4. Dismissed from institution for academic reasons

5. Dismissed from institution for non-academic reasons

6. Voluntarily withdrew from the institution

a. Mental health reasons

b. Health related injury

c. Academic major discontinued at institution

d. Financial reasons

e. Extenuating circumstances

f. Religious

g. Other (please specify)

7. Entered professional league

8. Other (please specify) 
4. Please feel free to offer any information or comments regarding the "special admit" process for student-athletes at your institution.

** If the respondent answered " 0 " to question 2, the survey skipped question 3 and showed them a modified version of question 4 which stated, "Please feel free to offer any information or comments as to why your institution does not have student-athletes who are admitted on a special admit basis." 